\title{
Modeling and Simulation of an Aerial Gliding Body in Free-Fall
}

\author{
Islam H. Elandy, A. N. Ouda, Ahmed M. Kamel, Yehia Z. Elhalwagy \\ Department of Guidance and Control \\ Military Technical College \\ Cairo, Egypt
}

\begin{abstract}
In order to investigate and analyze the dynamic behavior of the air-delivery munitions at separation and during flight, in this paper a complete nonlinear mathematical model is developed for the dynamics of a low drag unpowered aerial gliding body from first principles in open-loop configuration. The flying gliding body model under study has a plane-symmetrical configuration (symmetry about vertical plane) which has the largest lift plane. Therefore, the body can generate a large normal force, a large load factor, and a high lift/drag ratio in the normal direction in this plane. The development of a comprehensive semiempirical mathematical model of the body aerodynamics is described. The aerodynamic model used in the study is in the form of look-up tables. The goal of this paper is to introduce a development of a simulation model for the free fall flight dynamics and the trajectory of the gliding flying body at certain flight conditions by employing the 6-DoF (Degrees of freedom) nonlinear equations in the AeroSim Blockset and solving these equations using the classical Runge Kutta method (ODE4) with MATLAB and Simulink. Subsequently, this research shall be used later as an essential tool for enhancing stability by autopilot design. (Abstract)
\end{abstract}

Keywords - Nonlinear, Dynamics, Modeling, Simulation, 6DoF, Aerodynamics, Glider.

\section{INTRODUCTION}

Air-to-ground munitions are used to provide the ability to strike ground and sea-based targets from a distance without risking a large number of personnel, even when operating deep within enemy territory to evade defensive fire from the target area [2]. To achieve high accuracy of delivery and standoff capabilities of the aerial munitions, their dynamic characteristics are required to be investigated and analyzed as they are used in the aircraft avionics system to determine the time and conditions of release, as well as the initial states. Thus, accurate computations with a good level of precision is a very necessary requirement [5].

Modeling and simulation of a physical system are broadly utilized as fundamental tools to simulate, study, and analyze complicated engineering systems with a level of fidelity sufficient for design and implementation. For an aerial vehicle, such as an airplane, a 6-DoF complete simulation model with a high level of confidence gives designers and engineers the capability to examine and investigate new air vehicles prototypes or any changes or adaptations to existing ones prior to real evolution and implementation. So, it's considered as an essential tool in simulating the flights of aerospace systems with a promising level of fidelity in order to facilitate study and analysis of dynamic behavior, control system design, and also in designing the navigation and guidance systems [7].
Building up a flight simulation model begins with formulating the 6-DOF equations of motion for kinematic and dynamic models. Despite the fact that these equations of for a conventional aerial vehicle are known and are widely given in lots of references, the challenges arise from the difficulty to obtain good estimated calculations of the coefficients of the aerodynamic forces and moments and stability and control derivatives. Accurate computation of these derivatives is a major part in the development and validation of a high-fidelity simulation model. Experimental methods such as wind tunnel can be performed to calculate those derivatives, however this method is a hard task which requires many sets of experimental data and demands big efforts to resolve these data sets to define the control and stability derivatives for selected flight conditions. Alternatively, the geometric configuration of the aerial vehicle can be used to obtain a good estimation of these derivatives at certain atmospheric and flight conditions. For this research, a semi-empirical method (USAF Missile DATCOM) is employed to provide approximate calculations for the static stability and control derivatives. USAF Missile DATCOM is a widely used semi-empirical build-up technique to estimate aerodynamic performance for the preliminary design and analysis. According to given flight and atmospheric conditions and the geometry configurations of the body, Missile DATCOM can estimate its aerodynamic coefficients and stability derivatives $[8,9]$.

The remainder of this paper is structured as follows. In section II, the body model describing the vehicle geometrical and physical configuration is introduced. Different coordinate reference frames are introduced to give descriptions of the position and orientation of the vehicle in addition to forces and moments. The dynamic model of the aerial vehicle is introduced demonstrating the nonlinear mathematical differential equations of motion to describe the movement characteristics of the vehicle under study. The aerodynamic model is introduced and the calculations of the aerodynamic coefficients of forces and moments applied on the vehicle's airframe during flight are shown, the gravity model is described to consider the gravitational force, and the atmosphere model is described to obtain the air flow parameters during flight. In section III, the simulation results are shown for two cases of release. Section IV introduces the conclusion of this paper.

\section{PROPOSED MODEL}

In this section, the physical configuration of the body and the mathematical sub-models of the body, such as dynamic model, and aerodynamic model are described as follows: 


\section{A. Body Model}

The gliding body has a plane-symmetrical configuration with high aspect ratio wings and a set of four orthogonal rear fins in " $\mathrm{X}$ " form configuration, to achieve small zero-lift drag and high lift-to-drag ratio to make sure the flying vehicle's range is far enough. These configurations are also useful in case of deploying guidance and control techniques to maintain stability control and enhance hitting accuracy. Fig. 1(a, b) shows the airframe shape of the gliding body and the X-form fin configuration of the body's tail. Table I lists the geometry and inertia characteristics of the body.

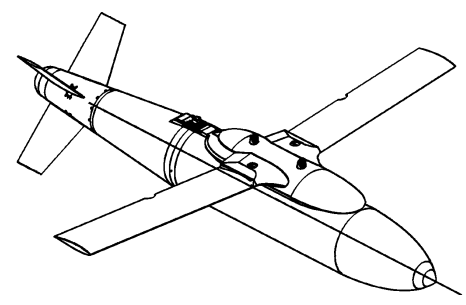

(a)

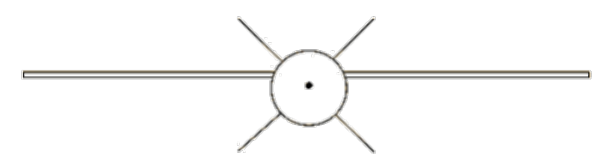

(b)

Fig. 1. (a) The gliding body airframe shape, (b) X-form fin configuration

TABLE I. CHARACTERISTICS of THE GLIDING BODY

\begin{tabular}{|l|l|}
\hline \multicolumn{1}{|c|}{ Parameter } & \multicolumn{1}{|c|}{ Value [unit] } \\
\hline Mass $(m)$ & $250[\mathrm{~kg}]$ \\
\hline Length $(L)$ & $2.4[\mathrm{~m}]$ \\
\hline Maximum Diameter $(D)$ & $0.29[\mathrm{~m}]$ \\
\hline Reference Area $\left(S_{\text {ref }}\right)$ & $0.4\left[\mathrm{~m}^{2}\right]$ \\
\hline Wing Span $(b)$ & $2.1[\mathrm{~m}]$ \\
\hline Chord $(c)$ & $0.24[\mathrm{~m}]$ \\
\hline Moment of inertia about $o x$ axis $\left(I_{x x}\right)$ & $4.1\left[\mathrm{~kg} \mathrm{~m}^{2}\right]$ \\
\hline Moment of inertia about $o y$ axis $\left(I_{y y}\right)$ & $52.55\left[\mathrm{~kg} \mathrm{~m}^{2}\right]$ \\
\hline Moment of inertia about $o z$ axis $\left(I_{z z}\right)$ & $54.2\left[\mathrm{~kg} \mathrm{~m}^{2}\right]$ \\
\hline
\end{tabular}

\section{B. Reference Frames}

To formulate a mathematical model for an aerial vehicle, the equations of motion should be defined and associated to a set of reference frames or coordinate systems. On account of this, the following three orthogonal coordinate systems were used to formulate the mathematical model [10]:

1. $\mathrm{OX}_{\mathrm{b}} \mathrm{Y}_{\mathrm{b}} \mathrm{Z}_{\mathrm{b}}$ - body-fixed reference frame with its origin at the vehicle's centre of mass.

2. $\mathrm{OX}_{\mathrm{w}} \mathrm{Y}_{\mathrm{w}} \mathrm{Z}_{\mathrm{w}}$ - wind reference frame.

3. $\mathrm{OX}_{\mathrm{g}} \mathrm{Y}_{\mathrm{g}} \mathrm{Z}_{\mathrm{g}}$ - Earth-referenced system with its origin at the vehicle centre of mass.
A sequence of rotations $\left(\mathrm{R}_{\varphi}, \mathrm{R}_{\theta}\right.$ and $\left.\mathrm{R}_{\psi}\right)$ by the Euler angles (roll $\varphi$, pitch $\theta$, and heading $\psi$ ) is used to transform any vector quantity in the body-fixed frame to the Earth-referenced frame. This sequence results in the transformation matrix $\mathrm{T}_{\mathrm{b}}^{\mathrm{g}}$

$\mathrm{T}_{b}^{\mathrm{g}}=\left[\begin{array}{ccc}\mathrm{C} \theta \mathrm{S} \psi & \mathrm{S} \varphi \mathrm{S} \theta \mathrm{C} \psi-\mathrm{C} \varphi \mathrm{S} \psi & \mathrm{C} \varphi \mathrm{S} \theta \mathrm{C} \psi+\mathrm{S} \varphi \mathrm{S} \psi \\ \mathrm{C} \theta \mathrm{S} \psi & \mathrm{S} \varphi \mathrm{S} \theta \mathrm{S} \psi+\mathrm{C} \varphi \mathrm{C} \psi & \mathrm{C} \varphi \mathrm{S} \theta \mathrm{S} \psi+\mathrm{S} \varphi \mathrm{C} \psi \\ -\mathrm{S} \theta & \mathrm{S} \varphi \mathrm{C} \theta & \mathrm{C} \varphi \mathrm{C} \theta\end{array}\right]$

Further rotations $\left(\mathrm{R}_{\alpha}, \mathrm{R}_{\beta}\right)$ by the angle of attack $(\alpha)$, and the angle of sideslip $(\beta)$ result in the transformation matrix $\mathrm{T}_{\mathrm{w}}^{\mathrm{b}}$ from the wind coordinate frame to the body-fixed coordinate frame. Fig. 2 shows the reference coordinate frames of the gliding body and the transition angles between them [1].

$$
\mathrm{T}_{\mathrm{w}}^{\mathrm{b}}=\left[\begin{array}{ccc}
\mathrm{C} \alpha \mathrm{C} \beta & -\mathrm{C} \alpha \mathrm{S} \beta & -\mathrm{S} \alpha \\
\mathrm{S} \beta & \mathrm{C} \beta & 0 \\
\mathrm{~S} \alpha \mathrm{C} \beta & -\mathrm{S} \alpha \mathrm{S} \beta & \mathrm{C} \alpha
\end{array}\right]
$$

Where, $\mathrm{C} \varphi$, S $\varphi$, etc. are $\cos \varphi$, $\sin \varphi$, etc.

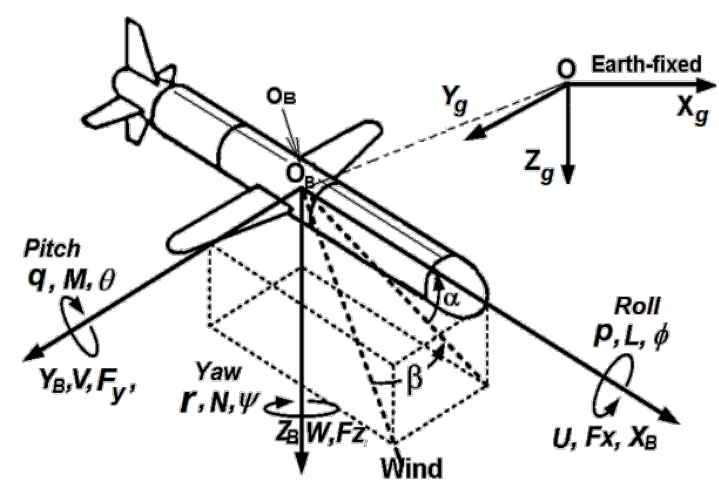

Fig. 2. Reference frames and the transition angles of the gliding body

\section{Dynamic Model}

In order to build up the dynamic model, the nonlinear differential 6-DOF equations of motion (EOM) for an aerial vehicle have been driven from general Newton-Euler translational and rotational dynamics and are used for modeling and simulation of the vehicle under study. To simplify the model, the equations of motion are developed based on the following assumptions [8]:

1. The vehicle is assumed as a rigid body.

2. The rotation of the earth is ignored.

3. The vehicle's mass, moments of inertia, and the location of the centre of mass are considered constant during any particular dynamic analysis.

4. The vehicle is symmetric in the $\mathrm{X}-\mathrm{Z}$ plane. 
The EOM in the body reference frame are as follows [3]:

Force equations:

$$
\begin{aligned}
& \dot{u}=r v-q w-g \sin \theta+X / m, \\
& \dot{v}=-r u+p w+g \sin \varphi \cos \theta+Y / m, \\
& \dot{w}=q u-p v+g \cos \varphi \cos \theta+Z / m
\end{aligned}
$$

Moment equations:

$$
\begin{gathered}
J_{x x} \dot{p}-J_{x z}(\dot{r}+p q)+\left(J_{z z}-J_{y y}\right) q r=L, \\
J_{y y} \dot{q}+\left(J_{x x}-J z\right) p r+J_{x z}\left(p^{2}-r^{2}\right)=M, \\
J_{z z} \dot{r}-J_{x z}(\dot{p}-q r)+\left(J_{y y}-J_{x y}\right) p q=N
\end{gathered}
$$

Kinematic equations:

$$
\begin{aligned}
& \dot{\varphi}=p+\tan \theta(q \sin \varphi+r \cos \varphi), \\
& \dot{\theta}=q \cos \varphi-r \sin \varphi, \\
& \dot{\psi}=(q \sin \varphi+r \cos \varphi) / \cos \theta
\end{aligned}
$$

Navigation equations:

$$
\begin{aligned}
& \dot{x}_{g}=u c \theta c \psi+v(-c \varphi s \psi+s \varphi s \theta c \psi)+w(s \varphi s \psi+c \varphi s \theta c \psi), \\
& \dot{y}_{g}=u c \theta s \psi+v(c \varphi c \psi+s \varphi s \theta s \psi)+w(-s \varphi c \psi+c \varphi s \theta s \psi), \\
& \dot{z}_{g}=-u s \theta+v s \varphi c \theta+w c \varphi c \theta
\end{aligned}
$$

For selected flight conditions and certain vehicle airframe, and from the dimensionless aerodynamic coefficients, the aerodynamic forces and moments are determined as follows,

$$
\begin{aligned}
& X=\bar{q} S_{r e f} C_{D}, \quad Y=\bar{q} S_{r e f} C_{Y}, \quad Z=\bar{q} S_{r e f} C_{L} \\
& L=\bar{q} S_{r e f} b C_{l}, \quad M=\bar{q} S_{r e f} c C_{m}, \quad N=\bar{q} S_{r e f} b C_{n}
\end{aligned}
$$

\section{Aerodynamic Model}

The purpose of the aerodynamic model is to describe the aerodynamic behavior of the vehicle's airframe and to provide promising estimated calculations for the aerodynamic forces and moments acting upon the body during its flight. It's useful to represent each one of the total aerodynamic forces and moments coefficients as a linear combination of individual contributions of various flight parameters [10]:

$$
\begin{aligned}
& C_{D}=C_{D_{0}}+\left(C_{L}-C_{L_{0}}\right) 2 \pi e A R+\left|C_{D_{\delta_{e}}} \delta_{e}\right|+\left|C_{D_{\delta_{a}}} \delta_{a}\right|+\left|C_{D_{\delta_{r}}} \delta_{r}\right|, \\
& C_{Y}=C_{y_{\beta}} \beta+C_{y_{\delta_{a}}} \delta_{a}+C_{y_{\delta_{r}}} \delta_{r}+\frac{b}{2 V_{T}}\left(C_{y_{p}} p+C_{y_{r}} r\right), \\
& C_{L}=C_{L_{0}}+C_{L_{\alpha}} \alpha+C_{L_{\delta_{e}}} \delta_{e}+\frac{c}{2 V_{T}}\left(C_{L_{\dot{\alpha}}} \dot{\alpha}+C_{L_{q}} q\right), \\
& C_{m}=C_{m_{0}}+C_{m_{\alpha}} \alpha+C_{m_{\delta_{e}}} \delta_{e}+\frac{c}{2 V_{T}}\left(C_{m_{\dot{\alpha}}} \dot{\alpha}+C_{m_{q}} q\right), \\
& C_{l}=C_{l_{\beta}} \beta+C_{l_{\delta_{a}}} \delta_{a}+C_{l_{\delta_{r}}} \delta_{r}+\frac{b}{2 V_{T}}\left(C_{l_{p}} p+C_{l_{r}} r\right), \\
& C_{n}=C_{n_{\beta}} \beta+C_{n_{\delta_{a}}} \delta_{a}+C_{n_{\delta_{r}}} \delta_{r}+\frac{b}{2 V_{T}}\left(C_{n_{p}} p+C_{n_{r}} r\right)
\end{aligned}
$$

The aerodynamic coefficients given in (9) can be obtained by experimental tests in wind tunnel or through real flight tests. However, because the experimental techniques are expensive and consume much time and effort, The United States Air Force (USAF) has implemented the Missile DATCOM, a semiempirical computer-based software provided with enormous sets of data with previous calculations of aerodynamics and analyses done experimentally for large collections of airframes. The Missile DATCOM accepts an input text file including the vehicle physical parameters and geometric characteristics (the shape and type of the wing/tail airfoil, the position of the center of gravity, the location of wing or tail, etc.), the flight conditions, the mass properties, and so on. The main parameters of the physical configuration of the vehicle and the flight conditions used in this study are included in the input file of Missile DATCOM and are given in Table II. The vehicle's body was divided into stations as to supply detailed information of the physical geometry of the vehicle to the USAF Missile DATCOM as shown in Fig. 3.

TABLE II. MISSILE DATCOM INPUT CONFIGURATION FILE PARAMETERS

\begin{tabular}{|l|l|}
\hline \multicolumn{1}{|c|}{ Parameter } & \multicolumn{1}{c|}{ Value [unit] } \\
\hline Reference area $\left(S_{\text {ref }}\right)$ & $0.4\left[\mathrm{~m}^{2}\right]$ \\
\hline Longitudinal reference length $(c)$ & $0.24[\mathrm{~m}]$ \\
\hline Lateral reference length $(b)$ & $2.1[\mathrm{~m}]$ \\
\hline Airspeed $\left(V_{T}\right)$ & $0.5,0.6,0.7$, \\
\hline & $0.8,0.9[\mathrm{M}]$ \\
\hline Angle of attack $(\alpha)$ & $-4,-3,-2,-1,0,1$, \\
& $2,3,4,5,6,7,8\left[^{\circ}\right]$ \\
\hline Angle of sideslip $(\beta)$ & $0\left[^{\circ}\right]$ \\
\hline Altitude $(h)$ & Mean sea level (MSL), \\
\hline
\end{tabular}

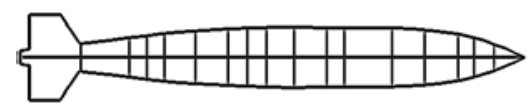

Fig. 3. The vehicle's body divided into 20 stations

The output file of Missile DATCOM gives the total aerodynamic forces and moments coefficients as multidimensional pages. Each page corresponds to a selected value of the Mach number, the sideslip angle, and the altitude. These coefficients are listed in each page as arrays versus the selected values of the angle of attack. Fig. 4 (a-d) shows the total aerodynamic forces and moments coefficients curves versus the angle of attack (from -8 to 4 [deg] at different air speeds (0.5, 0.6, 0.7, 0.8, 0.9 [M]) [11]. Assuming a sideslip angle of zero, it yields that the aerodynamics coefficients of the side force, the rolling, and the yawing moments, $\left(C_{Y}, C_{l}, C_{n}\right)$ are zeros. 


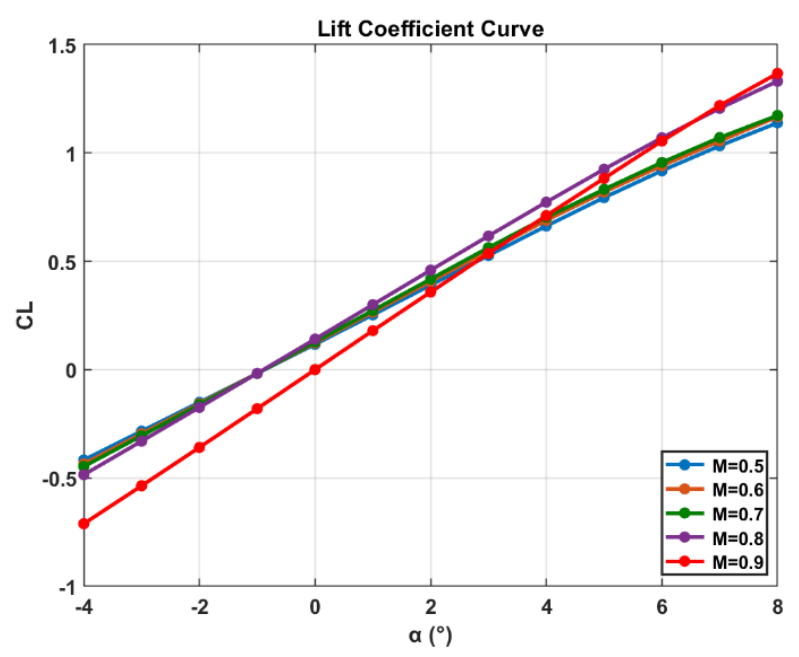

(a)

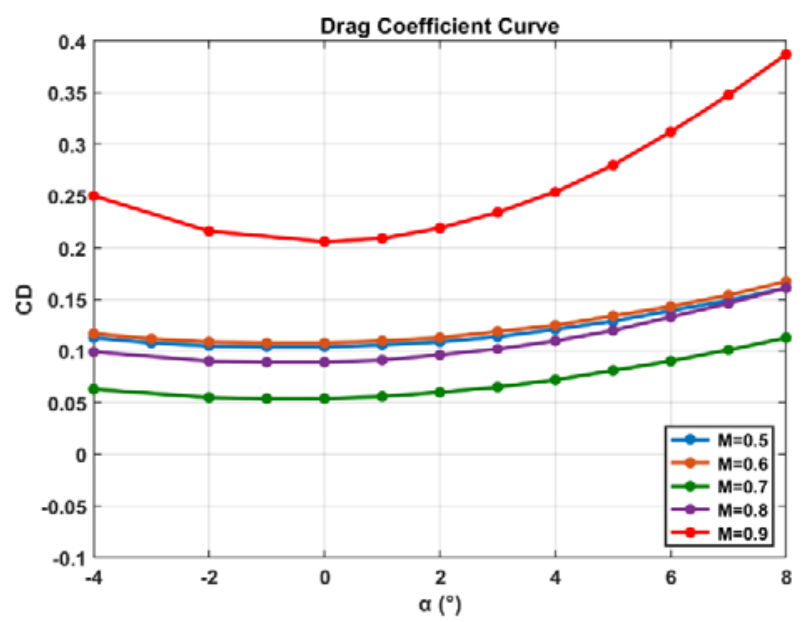

(b)

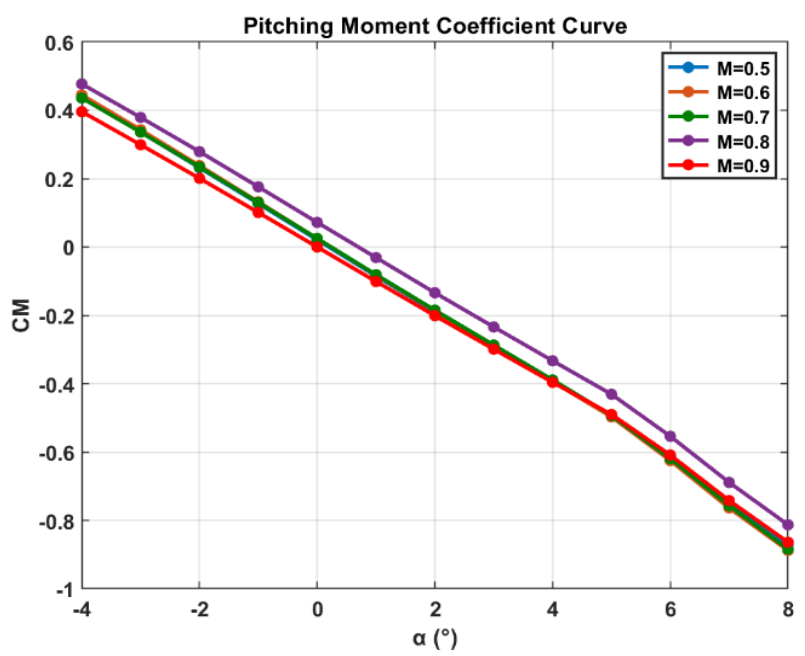

(c)

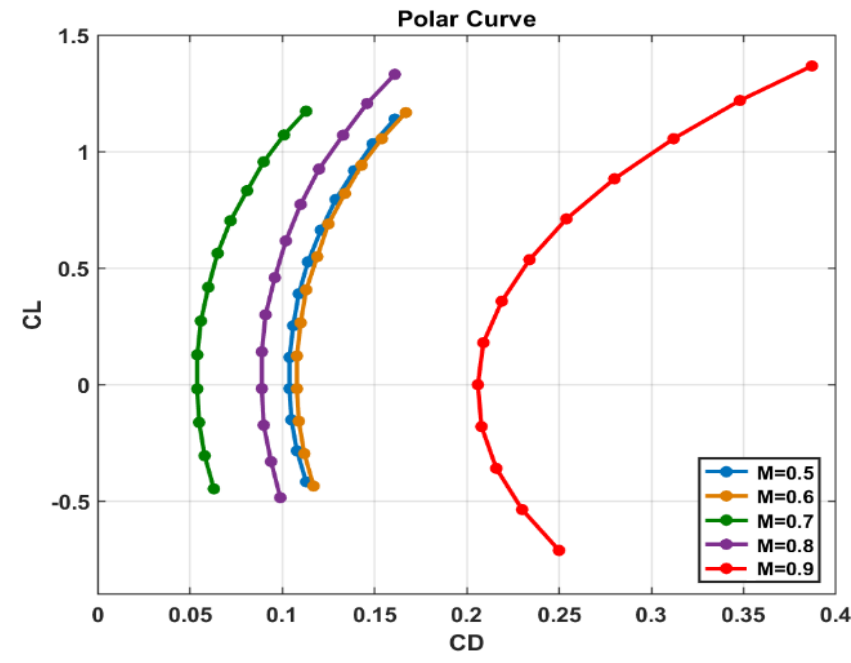

(d)

Fig. 4. Aerodynamics coefficients of forces and moments versus angle of attack for different Mach numbers, (a) Lift coefficient, (b) Drag coefficient, (c) Pitching moment coefficient, (d) Polar curve.

\section{E. Gravity Model}

Gravity model introduces the gravitational forces applied on the gliding body. The gravity model calculates the acceleration due to gravity acting at the current altitude due to the gravitational field of the Earth. The acceleration vector obtained from this model is coordinated in the Earth-referenced frame. Using Euler angles, the expression for the gravitational force coordinated in the Earth-referenced frame $\vec{F}_{g}^{\text {grav }}$ can be converted to the body-fixed frame as follows [12],

$$
\vec{F}_{B}^{g r a v}=\left[\begin{array}{c}
-\sin \theta \\
\cos \theta \sin \varphi \\
\cos \theta \cos \varphi
\end{array}\right]
$$

\section{F. Atmosphere Model}

The atmosphere model is used to obtain the air parameters (static pressure, air temperature, air density, speed of sound) at the instantaneous altitude. The model is developed by utilizing look-up tables which are interpolated to obtain air parameters that are corresponding to the current altitude within the operating altitude range of the vehicle [13].

\section{G. Wind Model}

In order to analyze and investigate the effect of atmospheric turbulence on the vehicle's flight, a simple simulation model of a von Karman turbulence shaping filter is developed and applied for three white noise sources with longitudinal, lateral, and vertical components. The design parameters of the filter are dependent on the magnitude of the background wind and the current altitude of the aerial vehicle. The effects of the wind shear that are introduced in this model are the pitch and yaw angular rates and accelerations. The pitch and yaw rates with respect to the wind are obtained from (11) and (12). Taking the numerical time derivatives of the pitch and yaw angular rates, the pitch and yaw accelerations can be obtained [10,14]. 


$$
\begin{aligned}
& q_{\text {wind }}=\frac{1}{u_{\text {vehicle }}} \cdot \frac{d w_{\text {wind }}}{d t} \\
& q_{\text {wind }}=\frac{1}{u_{\text {vehicle }}} \cdot \frac{d w_{\text {wind }}}{d t}
\end{aligned}
$$

\section{SIMULATION AND RESULTS}

In this section, a nonlinear 6-DoF simulation model is built up using the aeronautical simulation AeroSim blockset in MathWorks's MATLAB and Simulink environments. The AeroSim blockset contains blocks in which the basic aerospace dynamics are implemented. This can be very useful for the rapid setup of a complete nonlinear 6-DoF aerospace simulation model for any conventional air vehicle [14], [15]. The model has been implemented as a Simulink model as shown in Fig. 5. The nonlinear differential equations (3-6) were solved using the Runge Kutta (ODE4) method [4], [6]. Two cases of simulation were developed, the first is assuming release in no background wind turbulence, and the second one is assuming release in windy environment to take wind effect on the vehicle's flight states into account.

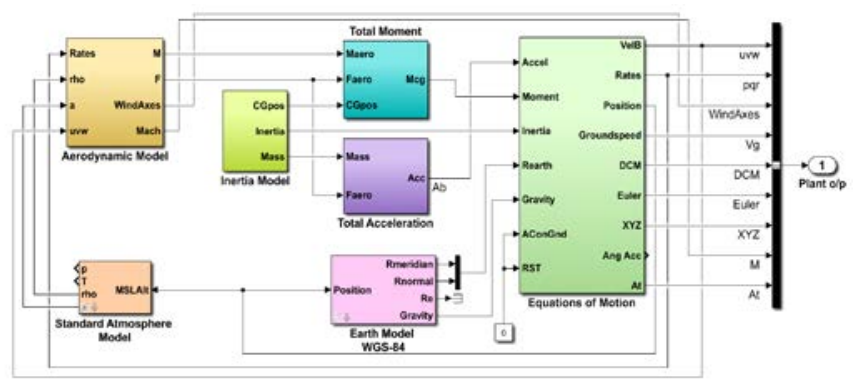

Fig. 5. 6-DoF Simulink block model

\section{A. Wind Excluded}

The vehicle is released at different initial conditions. It is assumed that the wind effect is ignored (non-turbulent environment). Fig. 6 (a-d) shows the flight simulation results for the vehicle release at an initial velocity of 0.7 Mach and altitude of $6 \mathrm{~km}$. Fig. 7 (a, b) shows the vehicle releases at different altitudes and at different initial velocities, respectively.

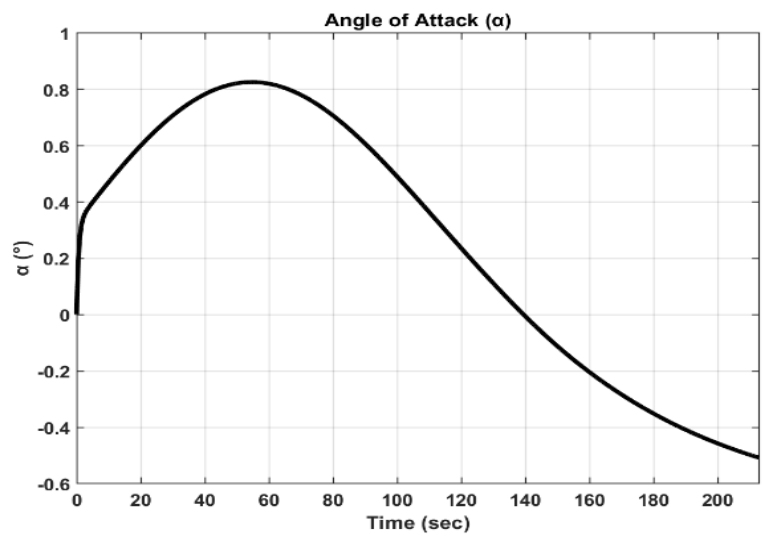

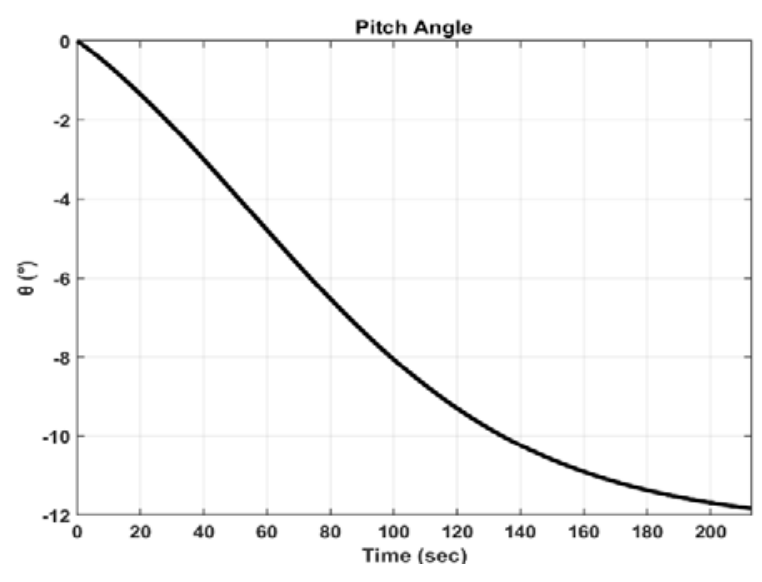

(b)

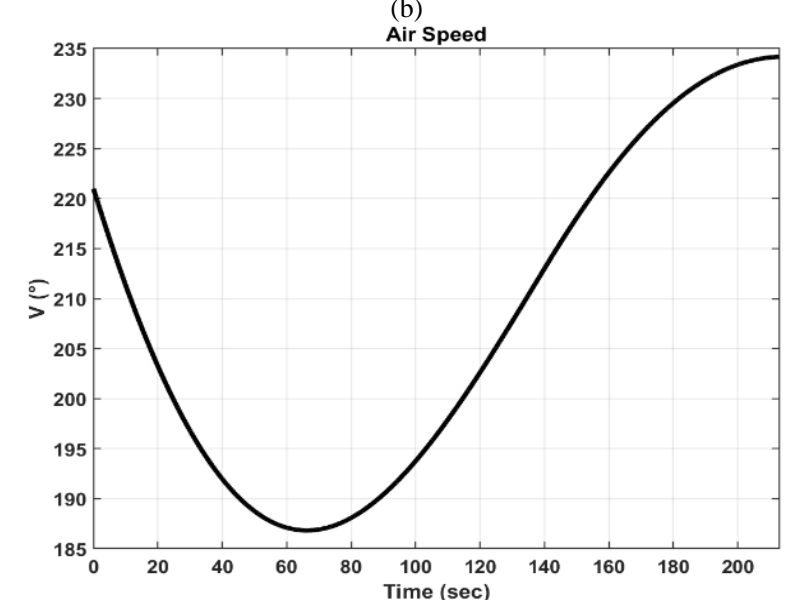

(c)

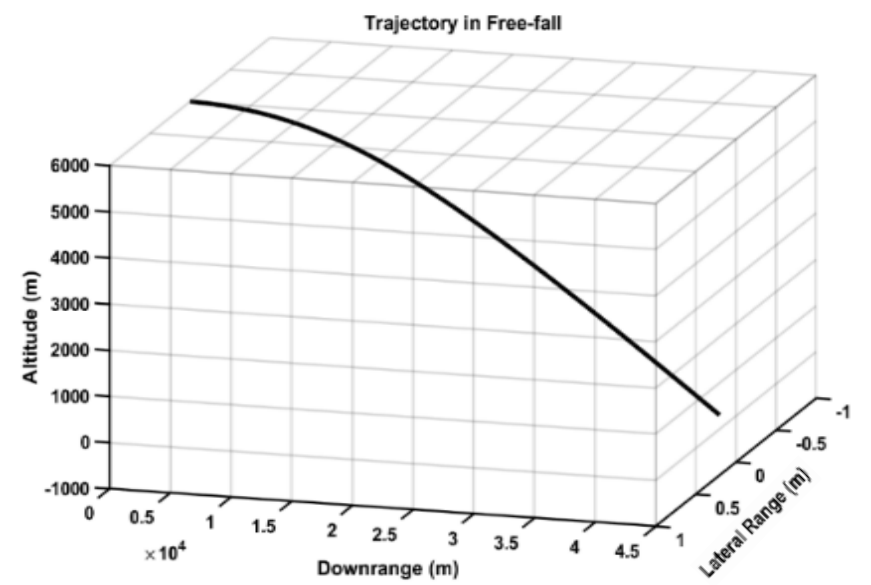

(d)

Fig. 6. (a) Angle of attack, (b) Pitch angle, (c) Air speed, (d) Flight 3D trajectory

(a) 


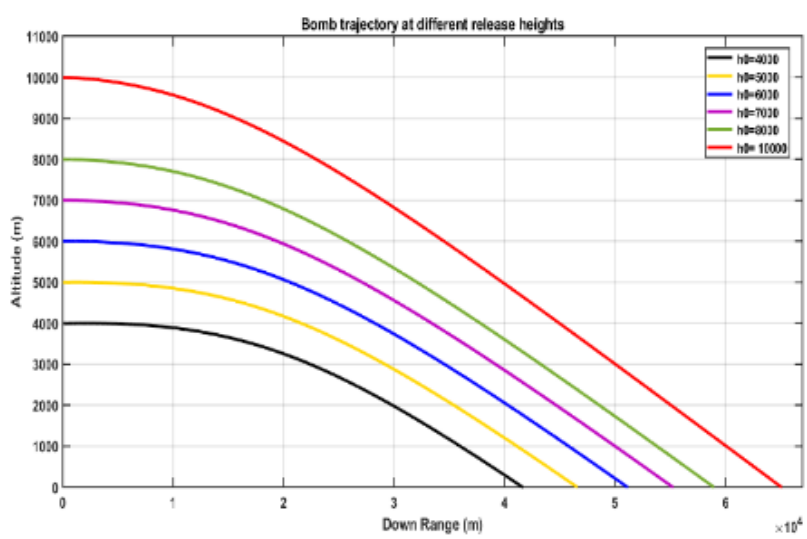

(a)

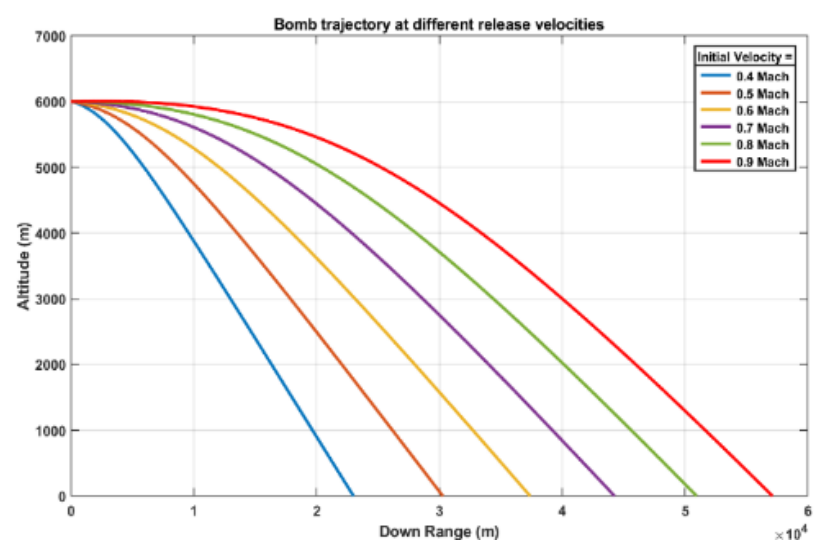

(b)

Fig. 7. (a) Vehicle release at different altitudes, (b) Vehicle release at different initial velocities

\section{B. Wind Included}

The vehicle is released in a turbulent atmosphere condition to take the effect of a time-varying background wind into account and investigate its influence on the vehicle's flight. Fig. 8 shows the wind velocity components $(U w, V w, W w)$ generated by the wind model for a chosen background wind with Earthreferenced velocity components of $(25,-10,0[\mathrm{~m} / \mathrm{s}])$ that are chosen for this simulation. For the sake of comparison, Fig. 9(ag) shows the flight states simulation results with wind effect and without wind effect. It can be noticed that the background wind considerably affects the behaviour of the vehicle's flight states. From the trajectory Fig. 9(a), calculations show that the coordinates of the vehicle's drop point on the Earth's surface without wind effect are $(43643,0,0) \mathrm{m}$, while the coordinates of the drop point under wind effect are $(43092,-1660,0) \mathrm{m}$.

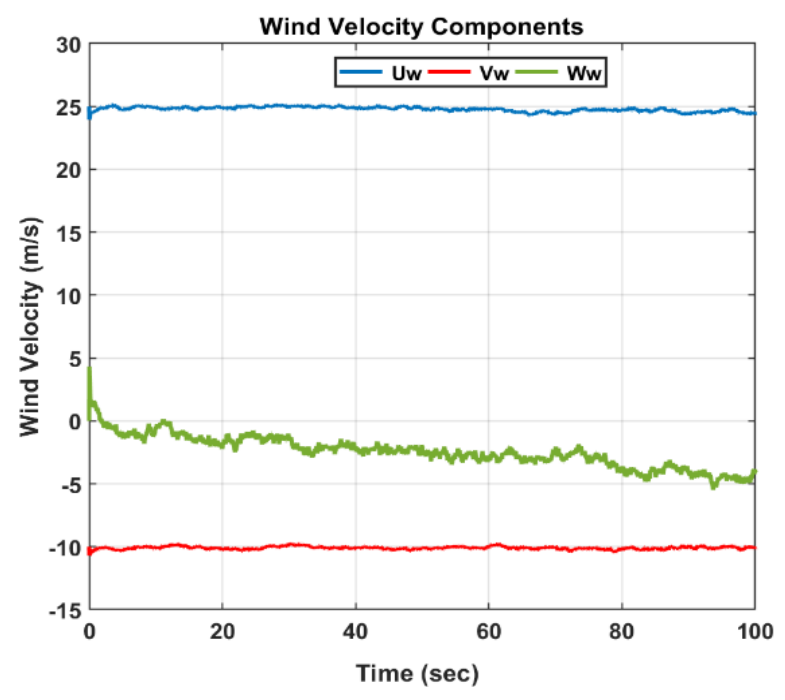

Fig. 8. Wind velocity components

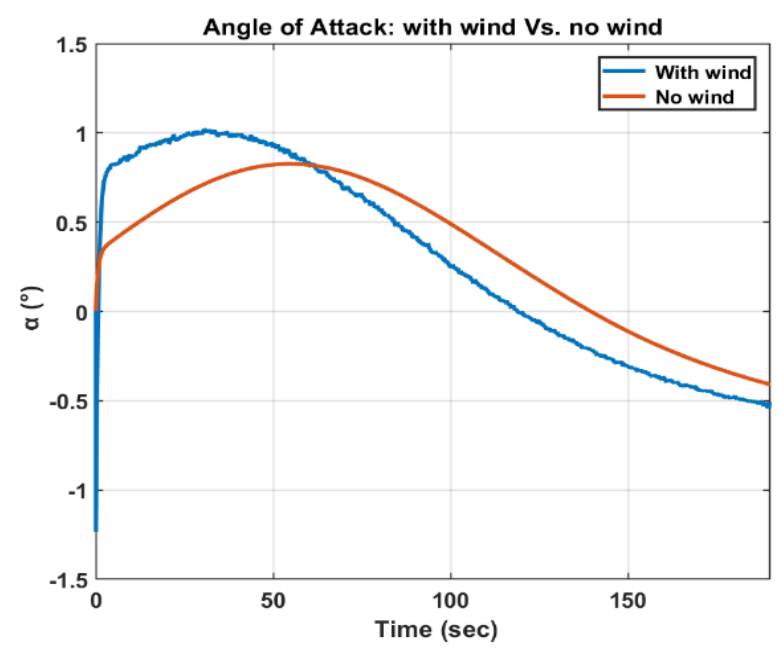

(a)

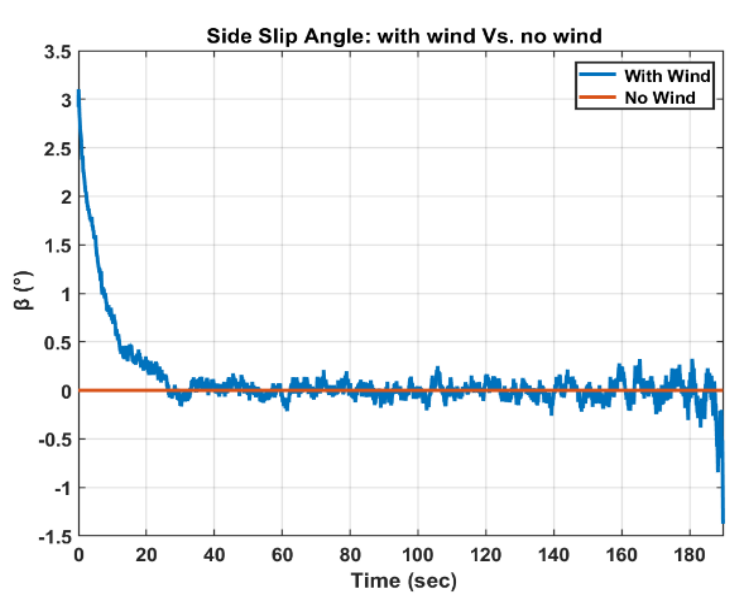

(b) 


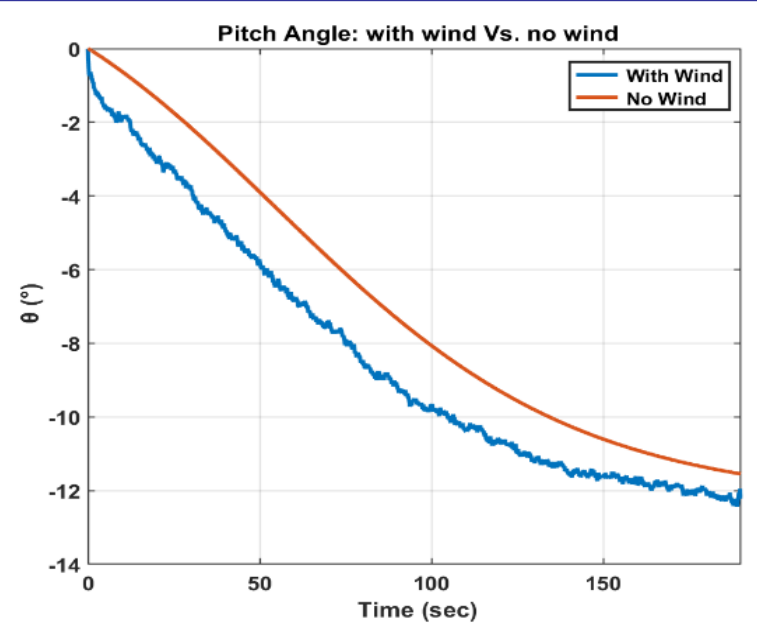

(c)

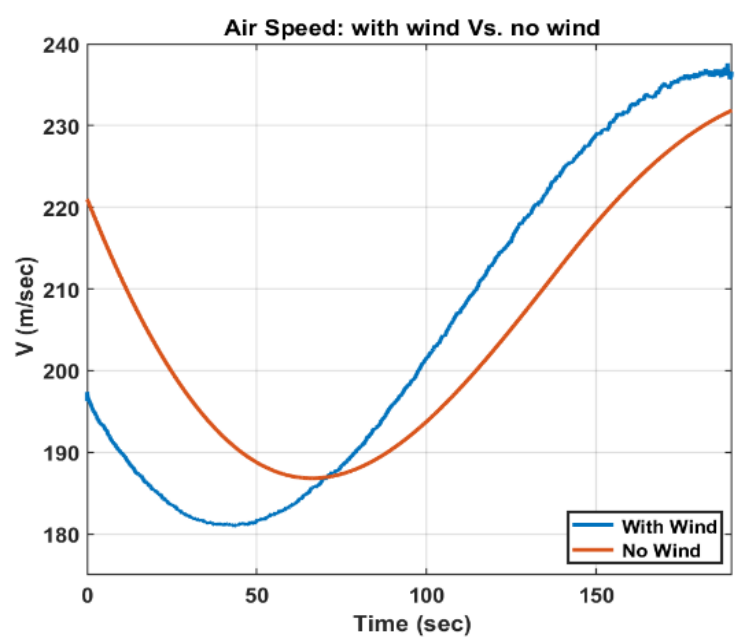

(d)

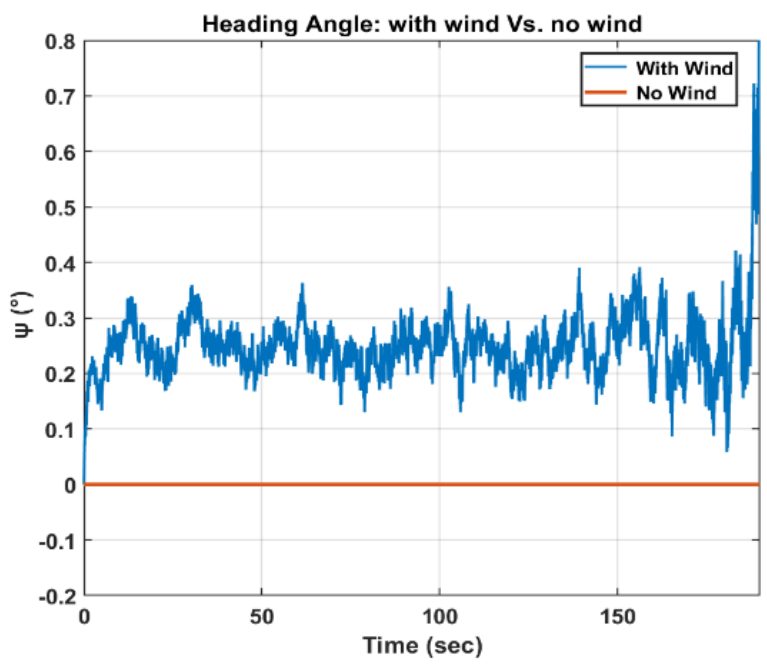

(e)

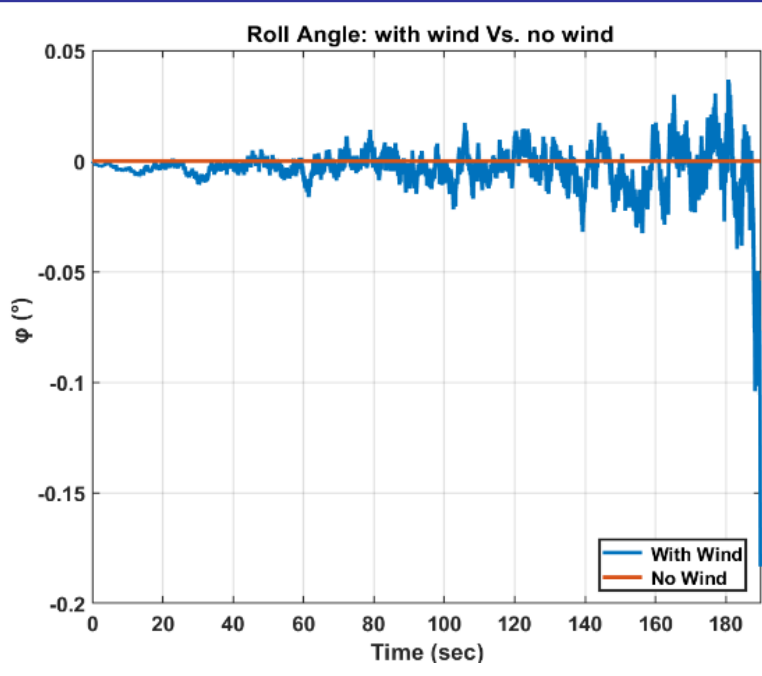

(f)

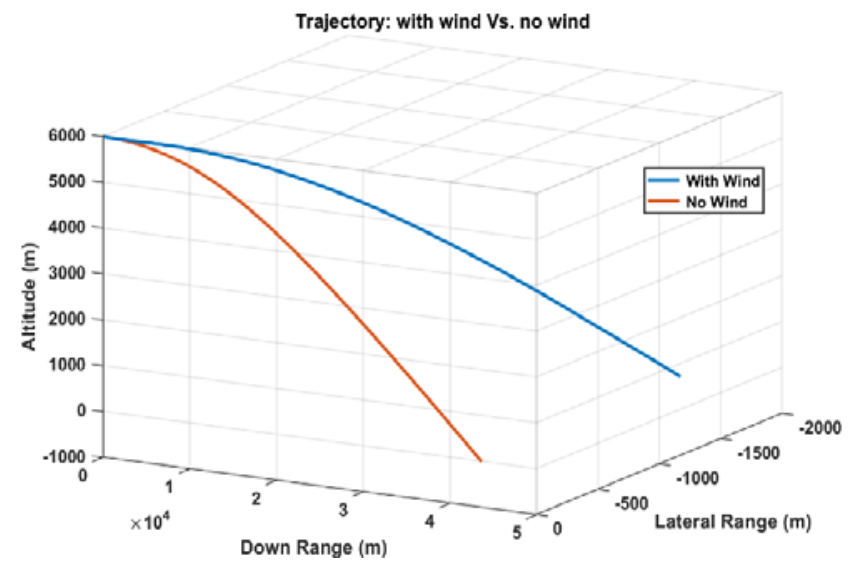

(g)

Fig. 9. Flight states with wind and without wind effect (a) Angle of attack, (b) Side slip angle, (c) Pitch angle, (d) Air speed, (e) Heading angle, (f) Roll angle, (g) Trajectory

\section{CONCLUSIONS AND FUTURE WORK}

This paper has presented a developed 6-DoF flight simulation model using the AeroSim blockset in the MATLAB and Simulink environments to simulate and analyze the dynamics of the vehicle under research. The simulation model included sub-models for the aerodynamics, gravity, atmosphere, and wind so that it can fulfil the purpose as a primary tool to simulate, study, and test the vehicle's flight prior to any design phases. The aerodynamic coefficients of forces and moments were estimated from the geometrical and physical dimensions of the vehicle's airframe using USAF Missile DATCOM software. Wind effect was investigated and it was shown that it has a significant influence on the flight behaviour, which makes it essential to consider the wind effect in the study and design. The current research suggests the following issues as future work: 
- Investigating further accuracy in the estimation of aerodynamic data by using advanced techniques such as CFD and wind tunnel testing.

- Developing a real-time visual 3D flight simulation system constructed based on Flight Gear.

- Developing guidance, navigation and control systems to convert the conventional free-fall munition into a guided vehicle.

\section{NOMENCLATURE}

\begin{tabular}{|c|c|c|}
\hline$U, V, W$ & $\begin{array}{l}\text { Translational velocities along the } \\
\text { body axes }\end{array}$ & {$[\mathrm{m} / \mathrm{s}]$} \\
\hline$p, q, r$ & Body angular rates & {$[\mathrm{deg} / \mathrm{s}]$} \\
\hline$X, Y, Z$ & $\begin{array}{l}\text { Drag, side force, and lift } \\
\text { aerodynamic forces }\end{array}$ & {$[\mathrm{N}]$} \\
\hline$L, M, N$ & $\begin{array}{l}\text { Roll, pitch, and yaw aerodynamic } \\
\text { moments }\end{array}$ & {$[\mathrm{Nm}]$} \\
\hline$x_{g}, y_{g}, z_{g}$ & Coordinates in Earth-fixed frame & \\
\hline $\bar{q}$ & Dynamic pressure & {$\left[\mathrm{N} / \mathrm{m}^{3}\right]$} \\
\hline$C_{D}, C_{Y}, C_{L}$ & $\begin{array}{l}\text { Drag force, side force and lift force } \\
\text { aerodynamic coefficients }\end{array}$ & \\
\hline$C_{l}, C_{m}, C_{n}$ & $\begin{array}{l}\text { Roll, pitch, and yaw moment } \\
\text { aerodynamic coefficients }\end{array}$ & \\
\hline$\delta_{a}, \delta_{e}, \delta_{r}$ & $\begin{array}{l}\text { Aileron, elevator, and rudder fin } \\
\text { deflections }\end{array}$ & [deg] \\
\hline$C_{D_{0}}, C_{L_{0}}, C_{m_{0}}$ & $\begin{array}{l}\text { Aerodynamic coefficients at zero } \\
\text { angle of attack }\end{array}$ & \\
\hline$C_{D_{\delta_{a}}}, C_{D_{\delta_{e}}}, C_{D_{\delta_{r}}}$ & $\begin{array}{l}\text { Drag coefficient aileron, elevator, } \\
\text { and rudder control derivatives }\end{array}$ & \\
\hline$C_{y_{\beta}}$ & $\begin{array}{l}\text { Side force coefficient sideslip } \\
\text { derivative }\end{array}$ & \\
\hline$C_{y_{\delta_{a}}}, C_{y_{\delta_{r}}}$ & $\begin{array}{l}\text { Side force coefficient aileron and } \\
\text { rudder control derivatives }\end{array}$ & \\
\hline$C_{y_{p}}, C_{y_{r}}$ & $\begin{array}{l}\text { Side force coefficient roll and yaw } \\
\text { rates derivatives }\end{array}$ & \\
\hline$C_{L_{\alpha}}$ & $\begin{array}{l}\text { Lift coefficient angle of attack } \\
\text { derivative }\end{array}$ & \\
\hline$C_{L_{\delta_{e}}}$ & $\begin{array}{l}\text { Lift coefficient elevator control } \\
\text { derivative }\end{array}$ & \\
\hline$C_{L_{\dot{\alpha}}}$ & $\begin{array}{l}\text { Lift coefficient angle of attack dot } \\
\text { derivative }\end{array}$ & \\
\hline$C_{L_{q}}$ & Lift coefficient pitch rate derivative & \\
\hline$C_{m_{\alpha}}$ & $\begin{array}{l}\text { Pitching moment coefficient angle } \\
\text { of attack derivative }\end{array}$ & \\
\hline$C_{m_{\delta_{e}}}$ & $\begin{array}{l}\text { Pitching moment coefficient } \\
\text { elevator control derivative }\end{array}$ & \\
\hline$C_{m_{\dot{\alpha}}}$ & $\begin{array}{l}\text { Pitching moment coefficient angle } \\
\text { of attack dot derivative }\end{array}$ & \\
\hline$C_{m_{q}}$ & $\begin{array}{l}\text { Pitch moment coefficient pitch rate } \\
\text { derivative }\end{array}$ & \\
\hline$C_{l_{\beta}}$ & $\begin{array}{l}\text { Roll moment coefficient sideslip } \\
\text { derivative }\end{array}$ & \\
\hline$C_{l_{\delta_{a}}}, C_{l_{\delta_{r}}}$ & $\begin{array}{l}\text { Roll moment coefficient aileron } \\
\text { and rudder control derivatives }\end{array}$ & \\
\hline$C_{l_{p}}, C_{l_{r}}$ & $\begin{array}{l}\text { Roll moment coefficient roll and } \\
\text { yaw rates derivatives }\end{array}$ & \\
\hline$C_{n_{\beta}}$ & $\begin{array}{l}\text { Yaw moment coefficient sideslip } \\
\text { derivative }\end{array}$ & \\
\hline$C_{n_{\delta_{a}}}, C_{n_{\delta_{r}}}$ & $\begin{array}{l}\text { Yaw moment coefficient aileron } \\
\text { and rudder control derivatives }\end{array}$ & \\
\hline$C_{n_{p}}, C_{n_{r}} r$ & $\begin{array}{l}\text { Yaw moment coefficient roll and } \\
\text { yaw rates derivatives }\end{array}$ & \\
\hline$V_{T}$ & Air speed & {$[\mathrm{m} / \mathrm{s}]$} \\
\hline & Oswald's coefficient & \\
\hline$A R$ & Wing aspect ratio & \\
\hline
\end{tabular}

\section{REFERENCES}

[1] A. N. Ouda, International Journal of Dynamics and Control (2017). doi.org/10.1007/s40435-017-0352-4

[2] S. Paunila and N.R. Jenzen-Jones, "Explosive Weapon Effects,” GICHD, Geneva, Final Rep. Feb. 2017.

[3] A. Elsayed Ahmed, A. Hafez, A. N. Ouda, H. Eldin Hussein Ahmed, and H. Mohamed Abd-Elkader, (2015), "Modeling of a Small Unmanned Aerial Vehicle," (Version 10000866). doi:10.5281/zenodo.1099968

[4] Eslam Nabil Mobarez, A. N. Ouda, and Abdelhalim Abdelnabi Zekry, "Mathematical Representation, Modeling and Linearization for Fixed Wing UAV," International Journal of Computer Applications 147(2):24-31, August 2016

[5] Andrzej Zyluk, "Sensitivity Analysis for Dynamic Models of Aerial Munitions," Journal of KONES Powertrain and Transport, vol. 20, No. 42013.

[6] Shady. A. Kader, Dr. Adel-ezzat El-henawy, and A. N. Ouda "Quadcopter system modeling and Autopilot Synthesis," International Journal of Engineering Research \& Technology, vol. III 2014.

[7] Ashraf M. Kamal, "Modeling, Analysis and Identification of Airplane Flight Dynamics," M. Eng. thesis, Military Technical College (MTC), Cairo, Egypt, April 2014.

[8] D. Jung * and P. Tsiotras, "Modeling and Hardware-in-theLoop Simulation for a Small Unmanned Aerial Vehicle," American Institute of Aeronautics and Astronautics, in AIAA Infotech@Aerospace 2007 Conference and Exhibit, Rohnert Park, California, paper AIAA 2007-2768, May 2007.

[9] Missile DATCOM User's Manual, USAF, Feb. 1998

[10] Kowaleczko, G., Zyluk, A., "Influence of Atmospheric Turbulence on Bomb Release," Journal of Theoretical and Applied Mechanics, JTAM-47,” Warsaw, 2009.

[11] Mansor, S., Ishak, I.S., Omar, W.Z., Rahman, A.B., Shamsudin, M.A., "Evaluation of Aerodynamic Derivatives of MK82 Bomb from Wind Tunnel Testing and Empirical Methods," International Conference on Mechanical, Automotive and Aerospace Engineering, ICMAAE-2," July 2013.

[12] A. M. Elsherbiny, A. M. Bayoumy, A. M. Elshabka, and M. M. Abdelrahman, "Inverse Simulation of Symmetric Flight of a Guided Gliding Subsonic Flying Body,” AIAA Modeling and Simulation Technologies Conference, Kissimmee, Florida, Jan. 2018.

[13] M. Cavcar, "The International Standard Atmosphere (ISA)" Anadolu University, Turkey, 2000.

[14] AEROSIM BLOCKSET Version 1.2 User's Guide, Unmanned Dynamics, LLC.

[15] Wang, X., and Cai, L. (2015), "Mathematical modeling and control of a tilt-rotor aircraft," Aerospace Science and Technology 47, 473-492. 